\title{
The Psychological Setup: The Third Front in the Battle Against the COVID19
}

\author{
Maria Grazia Spurio* \\ Director of Centre for Research and Psychological Studies Genius Academy via C.A. Jemolo Italy \\ *Corresponding author: Maria Grazia Spurio, Master in Neuropsychiatry and Forensic Psychology, Director of Centre for \\ Research and Psychological Studies Genius Academy via C.A. Jemolo 83 ROME, Italy
}

\begin{abstract}
ARTICLE INFO
Received: May 21, 2020

Published: 幽 May 26, 2020

Citation: Maria Grazia Spurio. The Psychological Setup: The Third Front in the Battle Against the COVID19. Biomed J Sci \& Tech Res 27(5)-2020. BJSTR. MS.ID.004569.
\end{abstract}

Keywords: Anxiety; Virtual reality; mind; Guided fantasy

\begin{abstract}
The emergency due to the spread of the COVID 19 virus has not only brought to light a health crisis, but also a psychological one, due to forced immobility, coexistence within families with relationship problems, as well as economic uncertainty. The mind could be considered the central goal of the healing process, because a relaxed state of mind and well-being strongly impacts on physical state in general and allows a rapid immunological defence in a time of difficulty. This article presents a perspective on highly innovative alternative solutions to traditional psychotherapy, for example in cases in which it is impossible because of sanitary emergency or geographical distance, such as the use of virtual reality and guided fantasy. The presence of the psychotherapist is essential only in some moments of this path, the experimentation gives the possibility of creating virtual environments in which one can venture into the path indicated by the guided fantasy. The applications can conveniently be downloaded to one device and used with the support of special viewers
\end{abstract}

\section{Introduction}

The historical moment we are going through has been defined by many as a period that is characterized by being an anxiety generator. Authors, virologists, political economists and the media are focusing on two topics in particular, probably because they are considered the most important ones for getting out of such a problematic and alarming situation. The first of the two arguments concerns the medical question related to the need to combat the covid19 infection, to stop the number of infected people and deaths, and the need to find a vaccine, in short, all the appropriate interventions to stem the medical problem of the virus crown. The other discussed topic concerns the economic consequences and the impact that the long period of social distancing will have in the short, medium and long term on economic and social life. However, there is a third topic which is much less talked about, at the same time very urgent, which consequences will be equally devastating if interventions in this sector will not be put in place. We are talking about the psychological sector, in particular the anxiety, caused by the situation in its entirety. The emotional reaction defined anxiety is, in this period, much more widespread than what normally occurs.

\section{Healing Tools and Methodologies}

Long periods of isolation in one homes, social estrangement, loneliness, fear of getting sick and dying, concern for one loved ones, fears of not having enough resources to go on in life, anguish that the situation may worsen.., this and much more, has triggered a sort of transverse time bomb that is making its effects felt and will be felt in a transversal way, both as regards health and also in the world of economics and work with incalculable disastrous effects. If therefore anxiety has always been widespread among the population, it can be considered a normal and natural reaction of adaptation of the individual to reality. Anxiety can occur both on the physical plane (with motor tension, headache, breathing difficulties, dizziness, palpitations, sweats, tremors, nausea, etc.), and on the psychic one (such as fear of losing control, of passing out, of dying , to make mistakes, to be refused, to relate to others, to concentrate, etc.) as well as on a behavioural level (with flight, 
avoidance and blockage). (Seligman, 1975). We can consider anxiety the expression, the symptom, of an emotional malaise and define it as a persistent, unpleasant internal state that is not easy to describe. According to DSM-IV-TR, the Diagnostic and Statistical Manual of Mental Disorders, disorders such as insomnia, sexual dysfunctions, anorexia, bulimia, depression, dissociative disorders and those of adaptation are usually accompanied by anxiety [1].

It is therefore clear that we are talking about a psychological phenomenon that has taken on the dimensions of a real problem, with malaise and discomfort, therefore, when the physicalpsychic-emotional-behavioural manifestations trespass a natural reaction to life's difficulties, it has to be viewed in a "pathological" perspective The consequences of such a pathology have a significant physiological impact, with a consequent lowering of the immune defences. So, we risk that high levels of anxiety that become excessive and exaggerated, in frequency, duration and intensity become a biological fragility that predisposes to the onset of the disease. Therefore, it is urgent to develop creative psychological protocols that can be a valuable aid to counteract the onset of the disease. On the other hand, the consequences of an anxious state of prolonged malaise on professional and work performances, and consequently, on economic level, make the recovery urgent in this time [2]. The mind is therefore the central goal of the healing process, because a relaxed state of mind and well-being strongly impacts on physical state in general and allows a rapid immunological defence in a time of difficulty [2].

A balanced and healthy mind also allows the individual to optimize ones creative cognitive resources and positively correlates with professional and economic performance, it does not break down but plans alternative business paths, it is curious and experiences crises, not feeling them as insurmountable difficulties or obstacles but as challenges to try to win [3]. But if the mind is the cornerstone of all psychological interventions designed to counteract excessive anxiety, with all its consequences, and it is able to encourage insights during creative moments, which psychological tools and methodologies can be used for this purpose? The rational and logical areas of the brain in this period are particularly stimulated by the amount of worrying news available on the various media every day. We often forget that a treasure trove of hidden and resources reside instead in the emotional brain areas, the limbic areas connected to memories, dreams to creativity, but also to irrational fears to existential phobias. Highly undervalued and neglected areas of the mind can make important contributions. A careful examination of brain functioning highlights how emotional management and creativity can be a valid help to free unexpected resources and successfully face paralyzing mental states of fear and discomfort related to unpleasant experiences [4].

One of the most effective way to overcome recurring and particularly traumatic thoughts, is to learn how to associate the same stimuli with different emotional experiences, not unpleasant, which exposure has to take place gradually and in safe contexts. In the absence of the possibility of accessing to places associated with specific phobic situations, or in the absence of the physical object, as in the cases of feeling of impending danger or pain, it is possible, with the help of a psychotherapist, to undertake the associative mental path, thanks to a correlation between dysfunctional emotions and positive and rewarding fantasy experiences [5]. In order to offer an alternative to the traditional psychotherapy, for example in cases in which it is impossible because of sanitary emergency or geographical distance, in the Research Study and Psychological Centre GENIUS ACADEMY, which I am the manager and director, has been organized gradual learning courses, live and on line. (https://www.genius-academy.it) However, highly innovative alternative solutions are currently being researched, such as the use of virtual reality and guided fantasy.

The presence of the psychotherapist is essential only in some moments of this path, in fact the therapist must necessarily suggest the most suitable fantasy for each person and situation, optimizing the great versatility offered by the guided fantasy. The experimentation gives the possibility of creating virtual environments in which one can venture into the path indicated by the guided fantasy. The applications can conveniently be downloaded to one device and used with the support of special viewers. On all these occasions, the person gradually gets used to appropriating a tool that will then be useful for life. As contact with one inner imaginative world continues, the proprioceptive, auditory, olfactory, visual, favoured and amplified sensations will gradually increase thanks to a total immersion in virtual reality. The guided fantasy allows access to a very deep level of emotional life, and also allows the exploration of movements and actions. In the imagination, the activation of the sensory system is real, exactly as it happens when traumatic episodes are recalled in a person's mind. Imaginative methods allow to offer people a faster and less direct way of reconstructing their emotions than the rational linguistic one [6].

Rational mode is instead continuously controlled by the inhibitory processes of consciousness. The images proposed are full of positive emotional values which are not immediately decoded by the subject, but which are perceived directly in terms of positive sensations. Guided fantasies are an expressive technique that is very useful for promoting and increasing self-awareness, increasing relaxation, relieving stress, they can be an effective tool for moving and activating people's internal resources, especially when they are blocked by problems of anxiety [7]. Recent studies suggest the importance of visualizations in promoting relaxation, healing processes, and in relieving stress [8]. Through guided fantasies, in the world of the imaginary, one can get in touch with one selves without anxiety. In the course of the imagined experience, deep aspects of oneself, emotions, as well as the awareness of one's resources on which the ability to react is based, may emerge. During viewing, rationality "takes a break", while visual images 
help to acquire greater self-awareness. Fantasy is a place, and a time, in which to give space to feelings and needs, that are usually not accepted and expelled from awareness, and experiment new roles and parts of oneself, to activate one's creativity, to imagine new possibilities and solutions to problems, and to difficulties. So, it would be interesting and appropriate in this historical moment, instead of intensifying disastrous images of disease death and poverty, to soliciting winning imaginative stories.

All this does not remain relegated to the world of fantasy and imagination. Changes and solutions experienced during visualization can be transferred to the waking state [5]. This is possible because imagining leads to brain activation that is identical to that present in the action. In other words, the activity of the mind, when something is visualized and imagined, is completely similar to that of when the same object is perceived in objective reality. Some studies have shown that through some types of guided fantasies it has been possible to influence the heartbeat, blood pressure, respiration, rhythms and forms of brain waves, motility and gastric secretions, the functioning of our immune system. In conclusion, through creative imagination it is possible to develop new ways of thinking, feeling, acting, with positive effects on the cognitive, affective and behavioural level [9]. The guided fantasy therefore constitutes a concrete and effective tool for working on the way in which difficulties are faced. This is particularly important in the present time, because through the activation of psychic healing states, already present in terms of internal resources, it is possible to use them in order to increase the personal awareness as well as introducing changes able to lead concrete and positive effects such as, for example, overcoming present difficulties, cultivating hope for the future, replace negative feelings with positive and experiment peaceful emotions [10-13].

\section{Conclusion}

A careful examination of brain functioning highlights how emotional management and creativity can be a valid help to free unexpected resources and successfully face paralyzing mental states of fear and discomfort related to unpleasant experiences. We often forget that a treasure trove of hidden and resources reside instead in the emotional brain areas, the limbic areas connected to memories, dreams to creativity, but also to irrational fears to existential phobias. Highly undervalued and neglected areas of the mind can make important contributions.

\section{References}

1. Cionini L (1991) Psicoterapia cognitiva. Teoria e metodo dell'intervento terapeutico. Roma, La Nuova Italia Scientifica, Italy.

2. Spurio MG (2017) The magic of caressing the mind by touching the body. Take care of depression, face up to cancer. A new frontier of psychooncology. Psychiatria Danubina 29: 383-388.

3. Bandura A, Barbaranelli C, Caprara GV, E Pastorelli C (1996) Multifaced impact of self-efficacy beliefs on academic functonning. Child Development 67: 1206-1222.

4. Spurio MG (2018) May we feed cancer? Insights Depress Anxiety. 2: 001 006.

5. Lazarus A (1996) L'occhio della mente. La forza dell'immaginazione per arricchire la personalità, Roma , Astrolabio, Italy.

6. Widmann C (2004) Le terapie immaginative. Roma: Edizioni Magi, Italy.

7. Napoli L (2010) I sogni come opportunità di cambiamento. Roma Salani editore, Italy.

8. Levenson H (1973) Reliability and validity of the I, P, and C sScales-A multidimensional view of Locus of Control. Paper presented at American Psychological Association Convention, Canada: Montreal: 9.

9. Spurio MG (2016) The new functional identity: a body that thinks, a mind that feels- frontiers and unexplored territories of the "body and mind zone", Psychiatria Danubina. supplement 1: 28

10. Desoille R (1991) Teoria e pratica del sogno da svegli guidato. Roma, Astrolabio, Italy.

11. Rotter JB (1966) Generalized expectancies for internal versus external control of reinforcement. Psychol Monogr 80: 1-28.

12. Sacco G (2003) Psicoterapia e sistemi dinamici. Nuove prospettive in terapia cognitivo- comportamentale. Milano, McGraw Hill.

13. Seligman ME (1975) Helplessness: On depression, development and death. San Francisco, CA: Freeman, USA.
ISSN: $2574-1241$

DOI: 10.26717/BJSTR.2020.27.004569

Maria Grazia Spurio. Biomed J Sci \& Tech Res

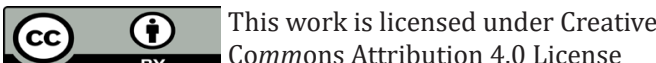

Submission Link: https://biomedres.us/submit-manuscript.php

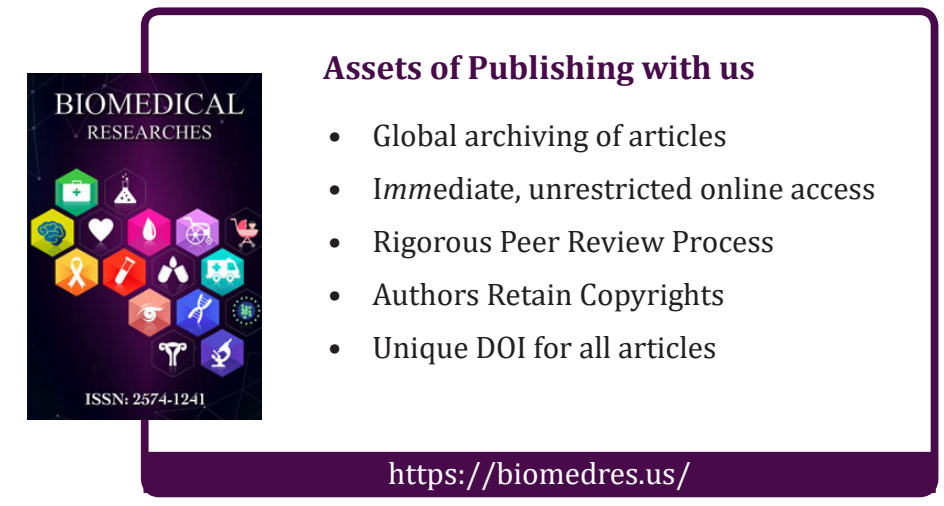

